\title{
Technological Properties of Ceramic Slurries Based on Silicon Carbide with Poly(vinyl alcohol) Addition for Shell Moluds Fabrication in Precision Casting Process
}

\author{
M. Malek*, P. Wisniewski, J. Szymanska, J. Mizera and K.J. Kurzydlowski \\ Faculty of Materials Science and Engineering, Warsaw University of Technology,
}

Wołoska 141, 02-507 Warsaw, Poland

\begin{abstract}
In this work technological properties of ceramic slurries based on silicon carbide powder with solid content $70 \mathrm{wt} \%$ were presented. These slurries were prepared for obtaining shell moulds in precision casting of Ni superalloys engine parts. The main binder was dispersion containing nanoalumina particles. Additionally poly(vinyl alcohol) with molecular weight $26000 \mathrm{~g} / \mathrm{mol}$ as $5 \mathrm{wt} \%$ water solution was used as a rheological modifier. To characterize silicon carbide: scanning electron microscopy images, chemical composition, Zeta potential and grain size were studied. Technological properties of ceramic slurries i.e.: plate weight test, viscosity, dynamic viscosity, density and $\mathrm{pH}$ were investigated. Properties of silicon carbide based ceramic slurries are very promising and their shell moulds are very perspective for future application in aerospace industry.
\end{abstract}

DOI: 10.12693/APhysPolA.129.528

PACS/topics: 81.05.Zx

\section{Introduction}

Nowadays, the investment casting process (often called "lost wax" casting) is a predominant technique widely used for the production of small sized precision cobalt, nickel, titanium and aluminum castings with complex geometries. It concerns fields such as military, marine, aerospace etc. The investment castings applied in aircraft engines requires the highest standards where ceramic shells molds are produced [1]. The mechanism of molds fabrication is based on the following steps. First, it is initiated by dipping a foam or wax pattern (with the same basic geometrical shape as the finished cast part) in ceramic slurry made of binder and solid phase (fused silica, zircon, alumina, yttrium etc.). The patterns are prepared in the way of injection molding. Then, the wax pattern is assembled with other wax components to form a metal delivery system (gate and runner system) [2] Advantage of waxes use is low melting points and low melt viscosities, allowing them easy to blend, inject, assemble and melt out without cracking the thin ceramic shell molds. Plastic patterns such as polystyrene, may also be used, to produce integrally cast turbine wheels and nozzles [3].

Afterwards, the dipped pattern is drained for sufficient time and then refractory powders are applied to the slurry coated pattern. Each coating contains fine ceramic layer, with coarse ceramic "stucco" particles embedded in its outer surface. The fine ceramic layer is the base for the inner face of the mold and determines the smooth surface of the pattern. The coarse stucco particles pre-

*corresponding author; e-mail: marcin.malek1987@gmail.com vent the shell from cracking or pulling away by bonding between individual coating layers [1].

The first coat (called as prime coat) is a crucial part of the mold due to impact on the final surface of the casting. Hence, there is a requirement of application of high viscosity slurry and finer stucco. Stucco is applied in different ways: by dipping the pattern into a fluidized bed, the rain fall method or simply by hand.

When strength of ceramic shell is not sufficient enough at high casting temperatures, there is a risk of bulging and cracking in a contact with the molten metal [4]. The mold should also be permeable to gases passing through the shell mold. Otherwise, air pressure increases within the mold [5]. In order to provide adhesion between the coats and avoid pulling the slurry away during drying, slurry which is applied into seal coat is not comprising stucco [6].

After dipping, sanding and drying process (from 16 to $48 \mathrm{~h}$ ), the final shell (with approximately $6 \mathrm{~mm}$ to $8 \mathrm{~mm}$ thickness) is removed from the wax in a steam autoclave at approximately 550 to $620 \mathrm{kPa}$ and in $15 \mathrm{~min}$ or less. Polystyrene patterns cannot be melted out in the autoclave, thus require flash dewaxing (by inserting the shell into a hot furnace at 870 to $1095^{\circ} \mathrm{C}$ ) [1, 2].

In the sintering process, the ceramic shells are preheated between 700 and $1000^{\circ} \mathrm{C}$ (above the liquidus temperature of the alloy being cast) and filled with the molten metal [1]. It allows to fill the complex geometry parts. Solidification process contributes to small changes in volume that takes effect as cracking of the shell during taking castings out of the ceramic shells [6].

Density, melting point, linear expansion coefficient, chemical composition, determine surface smoothness, accuracy and cost of the shell moulds. The ratio of fine/medium/coarse powder is determinant of the shell 
quality. Heating and firing treatment of the ceramic shell are related to alcohol and water evaporation. It results in volumetric shrinkage, tiny holes and cracking. Increasing the powder content in the slurry reduces these defects [7].

\section{Materials and method}

The subject of this measurement was silicon carbide powder signed 99C (Stanchem, Poland). To characterize powder SEM SU-70 (Hitachi, Japan) was used with $\mathrm{SE}$ mode and $5 \mathrm{kV}$ voltage. In addition, to identify powders particle size test was done using a laser diffraction device, Horiba LA-950 (Hitachi, Japan). Moreover, binder with particles of silicon oxide (Evonik) was used. For ceramic slurries preparation mechanical mixer Heidolph and PP reactor were used. Apart from studies of $\mathrm{SiC}$ powder, ceramic slurry was prepared and measured for technological properties characterization. Adhesion to plate was recorded every $15 \mathrm{~s}$. Total measurement time was $180 \mathrm{~s}$. The total contribution of the solid phase was $70 \%$ by weight. Modification of the ceramic slurry properties was based on addition one deflocculant: polyvinyl alcohol with molecular weight $26000 \mathrm{~g} / \mathrm{mol}$ as $5 \mathrm{wt} \%$ water solution. Dynamic viscosity was measured on Brokfield DV II+ viscometer using rotation 20-200-20 per minute. To characterize relative viscosity Zhan Cup $4 \#$ was used.

\section{Results and discussion}

In this article to preparation of ceramic slurries silicon carbide powder signed 99C green was used. The average particle size of studied silicon carbide was $21.8 \mu \mathrm{m}$ as $77 \%$ of amount is present in Fig. 1.

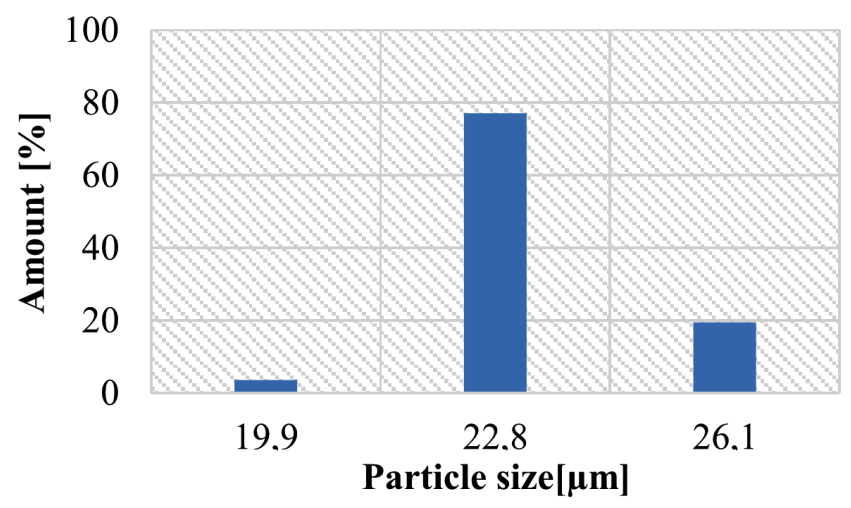

Fig. 1. Particle size distribution of silicon carbide powder.

Figure 2 presents the representative scanning electron microscopy (SEM) images of investigated powder. Studied images shown that $\mathrm{SiC}$ powder exhibits typically melted powder sharp-edged structure.

Figures 3-5 show adhesion test results of investigated ceramic slurries based on silicon carbide powder. As seen in all figures, first day of experiment exhibits the biggest

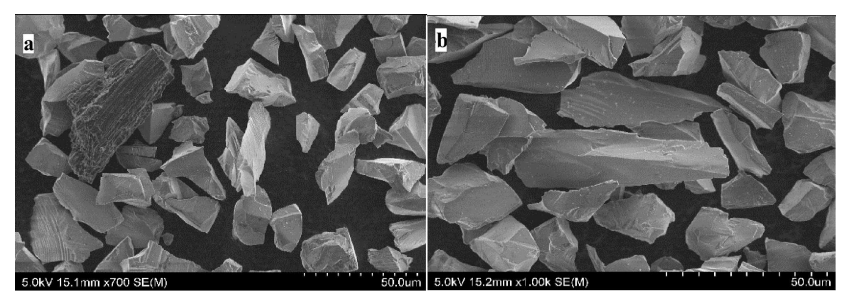

Fig. 2. SEM images of examined silicon carbide powder: (a) magnification $700 \times$, (b) magnification $1000 \times$.

value of weight. It is dependent on viscosity and density of ceramic slurries. Rest of curves profiles in the figures are very similar. Plateau was observed at $80 \mathrm{~s}$ of measuring in each case. The weight of ceramic slurries which were on a plate was $\approx 1.5 \mathrm{~g}$.

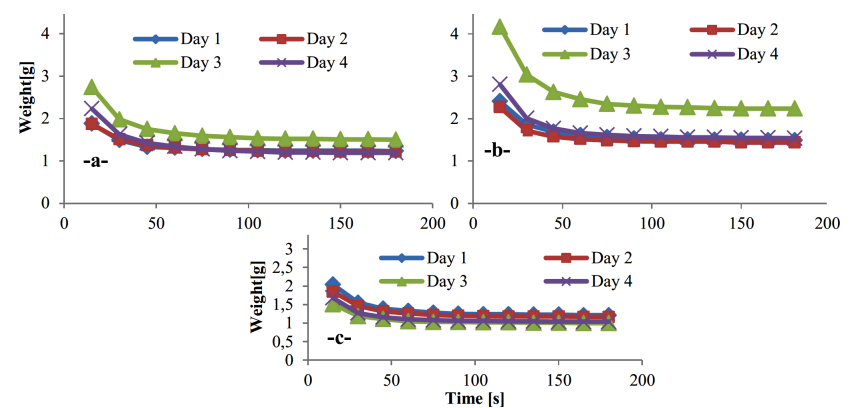

Fig. 3. Plate weight test distribution of examin ceramic slurries: (a) $6 \mathrm{wt} \%$ of PVAL, (b) $10 \mathrm{wt} \%$ of PVAL, (c) $15 \mathrm{wt} \%$ of PVAL.

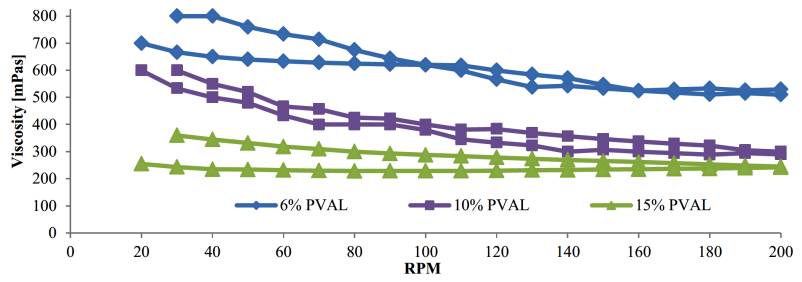

Fig. 4. Dynamic viscosity distribution of examined ceramic slurries.

Dynamic viscosity distribution of investigated ceramic slurries based on silicon carbide and new fabricated binder is presented in Fig. 4.

As seen in Fig. 4, ceramic slurries with 6 wt $\%$ addition of polyvinyl alcohol revealed the highest value of dynamic viscosity of $800 \mathrm{mPa}$, whereas addition of $10 \mathrm{wt} \% \mathrm{PVAL}$ caused decrease of viscosity to $600 \mathrm{mPa} s$ and $6 \mathrm{wt} \%$ to $400 \mathrm{mPa}$ s.

Figure $5 \mathrm{a}$ presents results of distribution of Zahn Cup $4 \#$ viscosity and weight after $120 \mathrm{~s}$. It shows that addition of PVAL in amounts 6 and $10 \mathrm{wt} \%$ is not adequate. The viscosity exhibits high value and rheological properties of ceramic slurries were decreasing. Addition of $15 \mathrm{wt} \%$ of PVAL revealed the lowest value of viscosity and meets the standard industrial requirements. Weight after $120 \mathrm{~s}$ of experiment using plate weight test was 


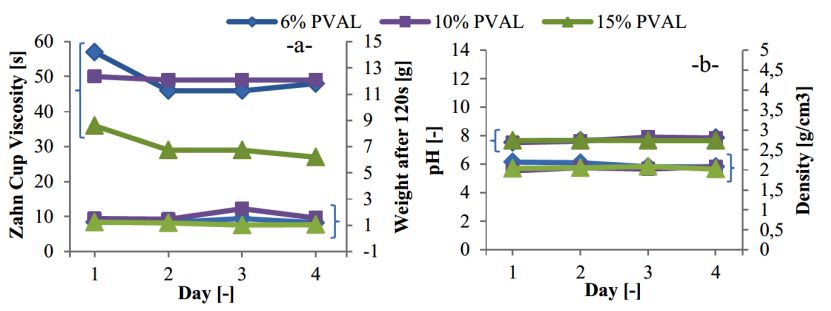

Fig. 5. Rheological properties of studied ceramic slurries: (a) Zahn Cup $4 \#$ and weight after 120 s of adhesion test, (b) $\mathrm{pH}$ and density.

changed every day and curves had comparable characters. Figure $5 \mathrm{~b}$ presents the results of parameters such as $\mathrm{pH}$ and density. Curves had very similar character. Density and $\mathrm{pH}$ of examined ceramic slurries are stable each measurement day. There were no significant changes on these parameters.

\section{Conclusions}

According to work assumptions, as well as in connection with the industrial requirements, these studies were focused to explore ceramic slurries, which are characterized by low density, relatively high ceramic powder content and the biggest than usually materials for shell mould fabrication value of thermal conductivity and comparatively low economic cost. The main subject was to use silicon carbide powder for preparation ceramic slurries for investment casting process. It has been proved that most desirable rheological parameters are exhibited by ceramic slurries with $6 \mathrm{wt} \%$ and $10 \mathrm{wt} \%$ amount of PVAL 26-88. Only slurry with 15 wt $\%$ amount of polyvinyl alcohol meets the standard requirements in investment casting process on industrial scale and they are very perspective for future fabrication of shell moulds. According to the works [8-12], many authors focus on properties of ceramic shell moulds. First of all it is difficult to compare technological properties, because authors of this article prepare ceramic shell moulds using new ecologist system based on new water binders and new ceramic fillers which are silicon carbides with different grain size on "prime coat" and "backup" layers. Second of all technological properties of ceramic moulds are strongly protected by companies engaged in the manufacture of moulds. Authors applied to the Poland Patent Office to get application and now have the Polish legal protection for this innovation $[8,9]$.

\section{Acknowledgments}

Financial support of Structural Funds in the Operational Programme - Innovative Economy (IE OP) financed from the European Regional Development Fund, Project "Modern material technologies in aerospace industry", No. POIG. 01.01.02-00-015/08-00 is gratefully acknowledged.

\section{References}

[1] R. Prasad, in: Science and Technology of Casting Processes, Ed. M. Srinivasan, Intech, Rijeka 2012, Ch. 2.

[2] F. Klocke, C. Ader, Direct Laser Sintering of Ceramics, Fraunhofer Institute for Production Technology IPT, 2003, p. 447.

[4] Z. Harun, N.H. Kamarudin, H. Mohd Taib, Adv. Mater. Res. 795, 732 (2013).

[5] G. Boothroyd, P. Dewhurst, W.A. Knight, Product Design for Manufacture and Assembly, 3rd ed., 2010, pp. 331, 559.

[6] C. Mahimkar, Ph.D. Thesis, 2011.

[7] W. Zhang, M.C. Leu, Investment Casting with Ice Patterns Made by Rapid Freeze Prototyping, 2000, p. 66 .

[8] M. Małek, P. Wiśniewski, H. Matysiak, K.J. Kurzydłowski, The ceramic slurries for ceramic shell moulds fabrication, P. 406518 (2013) — Polish Patents Application.

[9] M. Małek, P. Wiśniewski, J. Mizera, K.J. Kurzydłowski, The ceramic slurries for ceramic shell moulds fabrication, P. 412318 (2015) — Polish Patents Application.

[10] R. Haratym, R. Biernacki, D. Myszka, The ecological fabrication process of accurate castings in ceramic shell moulds, Oficyna Wydawnicza Politechniki Warszawskiej, 2008 (in Polish).

[11] M.R. Ismael, R.D. dos Anjos, R. Salomao, V.C. Pandolfelli, Refract. Appl. News 11, 16 (2006).

[12] H. Matysiak, J. Ferenc, Z. Lipiński, K. Grabarz, J. Michalski, K.J. Kurzydłowski, in: Materials Engineering 30, 239 (2009). 